\title{
Development of Content Based e-System Bulletin Board
}

\author{
Orven F. Mendoza ${ }^{1,2,3}$ \\ ${ }^{1}$ College Professor - Lyceum of the Philippines University - Batangas, Philippines \\ ${ }^{2}$ College Professor - STI College Balayan, Philippines \\ ${ }^{3}$ Master Teacher I - Lemery Senior High School, Philippines \\ Correspondence: Orven F. Mendoza, College Professor - Lyceum of the Philippines University - Batangas, \\ Philippines. E-mail: orvenmendoza09@yahoo.com.ph, orvenmendoza09@gmail.com
}

Received: May 9, 2018; Accepted: May 19, 2018; Published: June 29, 2018

\begin{abstract}
Communication is very important in our everyday living. Posting announcements and information is one way of communication. Normally, in some business leisure, school premises and community at large, if a person wants everybody to know important information, he uses notes and then post it in different areas. Traditionally, announcements, advertisements and important information have been provided by way of fixed sheets which are pasted to a backing. This manner is very tiring and energy and time consuming. Moreover, those important information, most of the times, are not read by the concerned personnel due to some presumptions that no new information is posted. With these, it becomes one of the major problems encountered by the teachers, employees, students and parents in Lemery Senior High School. This Research, Development of Content Based e-System Bulletin Board is a system that will lessen the time, energy and effort by the person informing important messages by applying the new technologies of moving led matrix display board through Arduino Microcontroller IDE. The system will also provide convenience to its user as it will just type in the laptop or desktop computer keyboard the announcement and display it digitally moving in the led matrix display board. Using the system, the school administrations will save time and effort on posting important announcements. The project is eye-catchy and it can be used to inform most of the students and teachers of something very important. The project is deemed to disseminate timely and important information's. The system will not only help the teachers and its employees but also all the students of Lemery Senior High School.
\end{abstract}

Keywords: Led Matrix Display Board, Arduino Microcontroller IDE

\section{Introduction}

Communication is very important in our everyday living. The term refers to all individuals who exchange such information with one another. Posting announcements and information is one way of communication. Normally, in some business leisure, school premises and community at large, if a person wants everybody to know important information, he uses notes and then post it in different areas.

Traditionally, announcements, advertisements and important information have been provided by way of fixed sheets which are pasted to a backing. This traditional approach suffers from the inability to quickly change the displayed message since it requires the use of a person to change the message. This manner is very tiring and energy and time consuming. Moreover, those important information, most of the times, are not read by the concerned personnel due to some presumptions that no new information is posted.

Lemery Senior High School bulletin boards, black or whiteboards, and corkboards are some of the older counterparts of this action research. Currently, the information posted or written in our school boards need to be both unpinned and taken down or erased manually when the information has passed already. Similarly, additional printing and posting of announcements should be done. This manner results from inability to quickly change and remove the information since a crew is needed in this occurrence.

To address these, the researcher decided to create a system and a device that will be used to display messages. An authorized person will just input to the computer or laptop the text messages he/she needs to inform everybody about important information. This project lessens the time, energy and effort by the person informing important messages. The system also provides convenience to its user. Electronic display boards signify high priority messaging, allowing communicating critical and time-sensitive information. 


\section{Objectives of the Study}

After careful analysis of the present situation of Information disseminations of the school administrator of Lemery Senior high School, the researcher came up with this study that aimed to develop and implement an e-Information dissemination system which would allow the users to easily change and update the important displayed messages.

Specifically, it sought answer to the following questions:

What are the problems encountered by the students and school personnel of Lemery Senior High School in knowing the upcoming events of the school?

Are the information's properly and timely disseminated to all concerned?

Is the bulletin board able to grab the readers' attention?

\section{Materials and Methods}

Table 1. Cost of the project

\begin{tabular}{llll}
\hline Item Name & Quantity & Unit Cost & Total Cost \\
\hline Led Matrix Display Board with Serial cable & 2 & $7,800.00$ & $15,600.00$ \\
Arduino Microcontroller with casing & 2 & 400.00 & 800.00 \\
& & Total: & $16,400.00$ \\
\hline
\end{tabular}

The table shows the materials needed with their corresponding cost in the Philippine currency.

\subsection{Design To Enhance Information Dissemination}

New design was plan and tested to provide a good way of Information dissemination and enhance the traditional bulletin board. Any computer or laptop can be used to send the announcement, advertisement and important messages. The user will just type-in the characters in the Arduino Microcontroller IDE program and then click "send". As a result, it will then be displayed to the e-System Bulletin Board.

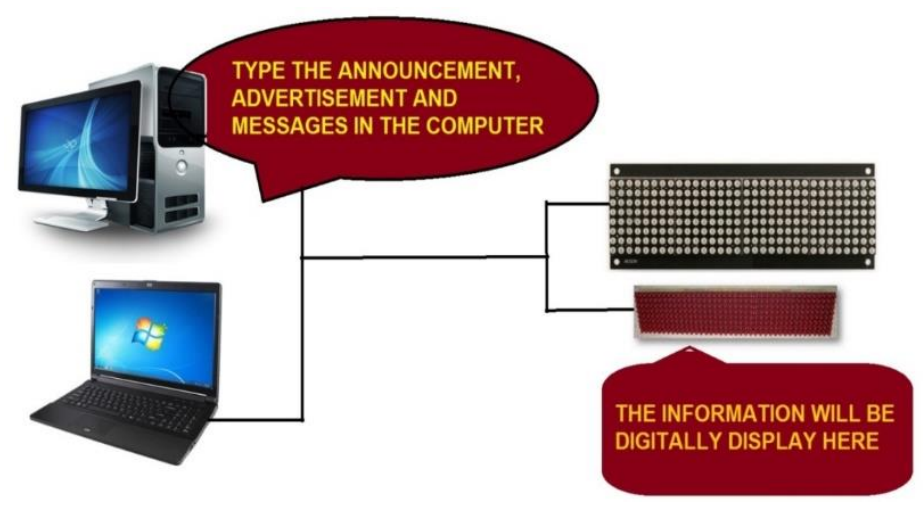

Figure 1. Instructional design and connection of e-bulletin board.

The research serve as a great solution for the problem in posting an announcements, advertisements and important messages to be able to know by the students and school personnel of Lemery Senior High School. Using the system, school administrations save time and effort on posting important announcements. The project is eye-catchy and it can be used to inform most of the students and teachers of something very important.

The authorized user use laptop or desktop computer to display the message to the electronic led matrix board. The user will type the message and then send it to the board. The message boards can only display a single color and a single line text message only. The project can only be used indoor. In case of computer or laptop power interruption, the message in the electronic board will not be displayed. This e-Information disseminations system is exclusively used for Lemery Senior High School. The e-system bulletin board is installed in the conspicuous area of the school like guard house, canteen and faculty room. 


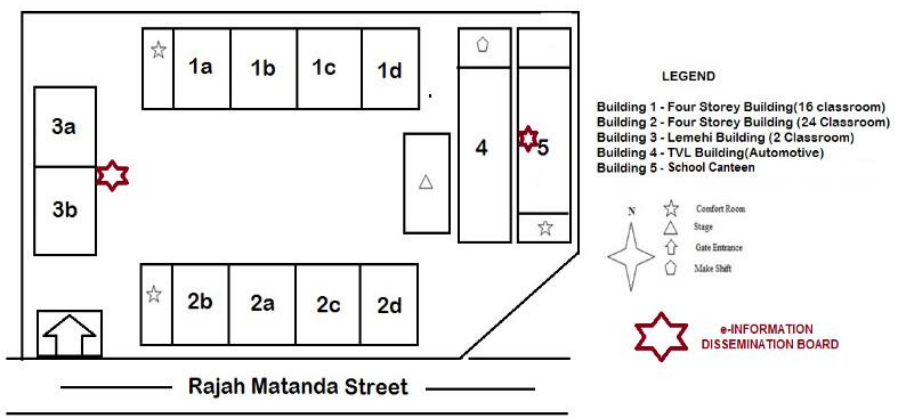

Figure 2. Location of e-System Bulletin Board in Lemery Senior High School

\subsection{Research Methodology}

\section{A. Participants and/or other source of data and information}

This study is centered on the Lemery Senior High School, a public educational institution, which has a composite teacher of fifty-two (52) and a total of one thousand eight hundred twenty four students (1824).

However, this study is extended to the non-teaching particularly the administrations primarily because it is where personal policies, directives and procedures emanate. This study utilized a random sampling procedure.

\section{B. Data Gathering Method}

Relevant information for the design of the device and its functional specifications were obtained. The developer gathered enough information needed to establish and develop the system.

This study used the descriptive applied-research to create an innovation to the existing bulletin board. The researcher utilized a questionnaire to gather data in which responses were tallied, analyzed and interpreted. As expected, the survey test among the teachers and non-teaching personnel yield data whose mean, median or mode can be a very good guide for dependable interpretation or analysis. With the aid of interviews, more accurate and reliable answer from persons who have actual knowledge of situation were obtained.

\section{Data Analysis}

Table 2. Conceptual Paradigm

\begin{tabular}{llllr}
\hline Input & & Process & Output & \\
\hline Technical skills & Survey & Technological approach in school & in \\
Knowledge and Ideas in computer & questionnaire & announcements and timely information \\
programming & dissemination & & \\
Problems encountered in Information & Statistical & & \\
disseminations & Treatment & & \\
\hline
\end{tabular}

The purpose of this research project was to have a system that can be used in information disseminations among the teachers, employees, parents and students. The collected data for this project were analyzed and were given focus; The proponent conduct a benchmarking on how some school creates information disseminations. The researcher visited public Secondary school in the district of Lemery and found out that they are also practicing/exercising the same way of publishing announcements. The researcher also went to some establishments like banks and some other government offices. Advocate find out what materials and tools where ideal to use in providing a well, strong and excellence information dissemination project.

\subsection{Results and Discussion}

Different electronic components were chosen and used in the construction of the device that is capable of providing the required output of the project. The researchers conducted actual questioning and surveys in support to the desired objectives. Findings of this research reveal that this project will really help the community of the school.

The following are the results and the analysis done from the data. 
Table 3. Problems encountered by the students and school personnel of Lemery Senior High School in knowing the upcoming events of the school. $\mathrm{N}=105$

\begin{tabular}{lccc}
\hline Problems encountered & Frequency & Percentage & Rank \\
\hline Lack of communication & 36 & 34 & 2 \\
Eye-catchy bulletin board & 44 & 42 & 1 \\
Focus / Interest in school announcement & 8 & 8 & 4 \\
Proper authority for information dissemination & 17 & 16 & 3 \\
\hline
\end{tabular}

It can be gleaned from the table that Eye-cathy bulletin board is the main problem being encountered by the students and school personnel's of the Lemery SHS in Information disseminations.

Table 4. Timeliness in Information dissemination. $\mathrm{N}=105$

\begin{tabular}{llll}
\hline I see the school announcement: & Frequency & Percentage & Rank \\
\hline Right after it is posted & 15 & 14 & 3 \\
1-3 days after posted & 38 & 36 & 1 \\
One week after posting & 36 & 34 & 2 \\
Two - three weeks after posting & 10 & 10 & 4 \\
One month after posting & 6 & 6 & 5 \\
\hline
\end{tabular}

It can be gleaned from the table that most of the time it take a day up to one week for the students and school personnel to see the important message or school announcement from the concerned office or authority.

Table 5. Characteristics of e-System Bulletin board in grabbing's reader attention after applying the new system design

\begin{tabular}{llll}
\hline The bulletin board is: & Frequency & Verbal Interpretation & Rank \\
\hline Presentable & 2.029 & Agree & 3 \\
Always with current school information & 1.438 & Strongly Agree & 2 \\
Eye-catchy & 1.305 & Strongly Agree & 1 \\
COMPOSITE MEAN & 1.591 & Strongly Agree & \\
\hline
\end{tabular}

The composite mean of 1.591 verbally interpreted as Strongly Agree showed that the respondents find the eSystem bulletin board as an effective tool in grabbing the reader's attention.

\section{Conclusion and Recommendation}

\subsection{Conclusions}

From the findings of the study, the following conclusions were drawn:

1. The main problem being encountered by the students and school personnel's of the Lemery SHS in Information disseminations is to get the reader's attention through eye catchy bulletin board.

2. It takes a day up to one week for the students and school personnel to see the important message or school announcement from the concerned office or authority.

3. The new design to enhance information dissemination was made to replace the traditional bulletin board

\subsection{Recommendations}

Based on the findings and conclusions, the researchers recommend the following:

1. The size of the led matrix display board should be considered. The bigger the size the better.

2. Additional technology like Radio Frequency (RF) and some touch screen based application can also be adopted in sending message or announcement to the e- board.

3. Use solar power system as an alternative of power supply for the e-board and computers.

4. Study the ways on how to have an automatic message/announcement deletion through a period of time. 


\section{References}

Desmukh, V. R., Karande, N., Dpatil, S. S., \& Tamboli, A. S. (2016). Led Scrolling Display using Android Phone. Karad Maharahastra India. January 2016.

Kayode, S. O. (2014). "64-by-8 Scrolling Led Matrix Display system” Okure Ondostate,Nigeria March 2014.

Ravindra, R. S. (2008). Moving Message using Dot Matrix Display. R.K.N.E.C. Nagpur, Maharashtra, India. January 2008.

\section{Unpublished Researches}

EACOMM Corporation. (2008). "Wireless Data Transmission using SMS" Eastwood City Cyberbank, Tagumbayan, Quezon City, Philippines. May 2008.

Zandro, D. C., \& Czarina, G. (2009). SMS-Based Led-Matrix Display Board. STI College Balayan, Ermita Balayan Batangas Philippines. March 2009.

\section{Books}

Adventures in Arduino by Becky Stewart. (2015). Tutorial on Arduino Basic Starter Kit by Elexhub.

\section{Electronic Sources}

A LCD Monitored Arduino News Ticker Based on MAX7219 Dot Led Matrix Devices by floriswouterlood. https://thesolaruniverse.wordpress.com/2016/05/20/a-lcd-display-monitored-arduino-news-ticker-based-onmax7219-dot-led-matrix-devices/

Multiple Led Matrices With Arduino by Tumaku Retrieved from http://www.instructables.com/id/Multiple-LEDMatrixes-with-Arduino/

\section{Copyrights}

Copyright for this article is retained by the author(s), with first publication rights granted to the journal.

This is an open-access article distributed under the terms and conditions of the Creative Commons Attribution license (http://creativecommons.org/licenses/by/4.0/). 